\title{
Vibration induced neurophysiological and electron microscopical changes in rat peripheral
}

\section{nerves}

Kwang-Yuan Chang, Shien-Tsong Ho, Hsin-Su Yu

\begin{abstract}
This study was conducted to clarify the effects of vibration on the peripheral nerves. Rat tails were exposed to vibration (acceleration $56.9 \mathrm{~m} / \mathrm{s}^{2}$, frequency $60 \mathrm{~Hz}$, amplitude $0.4 \mathrm{~mm}$ for two or four hours daily, six days a week. The maximum motor conduction velocity (MCV), the amplitude of evoked response, and the motor distal latency were measured on rat tail nerves every two months. Thin sections of tail nerves were examined under the electron microscope after 200, 500 , and 800 hours of vibration. Neurophysiological and ultrastructural changes in tail nerves increased with the dose of vibration. In the groups exposed to vibration the MCVs were significantly reduced after a vibration time up to $\mathbf{4 0 0}$ hours, whereas the motor distal latency was not delayed significantly until 600 vibration hours. The ultrastructural changes were (1) detachment of the myelin sheath from the axolemma, (2) constriction of the axon, (3) protrusion of the myelin sheath into the axon, (4) accumulation of vacuoles in paranodal regions, and (5) dilatation of the Schmidt-Lanterman incisures. The ultrastructural changes induced by vibration in the paranodal regions and myelin sheaths were possibly responsible for the reduction in MCVs.
\end{abstract}

(Occup Environ Med 1994;51:130-135)

Vibration syndrome is a multisystem disorder of the peripheral circulation, nerves, muscles, bones, and joints of the hands and arms. One of the most frequent complaints of patients is numbness or paraesthetic feelings in the hands and fingers. Objectively, reduction of the sense of touch and in some cases wasting of the muscles has been shown. The pathophysiological and clinical findings in vibration induced neuropathy are poorly understood. ${ }^{1}$

Investigations concerning the effects of vibration on the peripheral nerves usually involve measurement of nerve conduction velocity, evaluation of sensory functions, histopathological examination, and examination by electron microscopy. It has been reported that long term exposure to vibration may result in reduction of the conduction velocity of the median and ulnar nerves of the upper extremities. ${ }^{23}$

Antidromic sensory nerve conduction velocities of the median nerves in vibration disease were significantly slowed compared with those in healthy controls. ${ }^{4}$ Sensory disturbances, such as raised thresholds of vibratory sensation, pain, tactile depth perception, and two point discrimination, were also found in workers exposed to vibration. ${ }^{25-9}$ The morphological changes in the peripheral nerves of skin specimens obtained by biopsy from fingers of patients with traumatic vasospastic disease showed myelin damage and loss of nerve fibres in association with Schwann cell proliferation, collagen formation, and perineurial fibrosis. ${ }^{1011}$ In animal models, ultrastructural changes in the peripheral nerves due to local vibration were found. ${ }^{12} 13$ Simultaneous studies on the structural and neurophysiological changes in the peripheral nerves subjected to prolonged local vibration are, however, still few and incomplete. The object of this study was to investigate the ultrastructural and neurophysiological changes induced in rat tail nerve by vibration.

\section{Materials and methods}

SUBJECTS AND EXPOSURE

Thirty six male Wistar rats weighing about $360 \mathrm{~g}$ each were used. They were divided into three groups, each consisting of 12 rats of similar body weight. Group 1 was the control group. Group 2 was exposed to vibration for two hours daily and group 3 for four hours daily, six days a week.

During exposure, each rat was put into a cage with its tail extended out of the cage, and the tail was stuck to the shaker with a piece of $3 \mathrm{M}$ poriferous adhesive tape. Each control rat was put into a cage, placed near the operating shaker, and exposed to its noise for four hours daily. The room temperature was $20^{\circ}$ to $25^{\circ} \mathrm{C}$ in winter and $28^{\circ}$ to $33^{\circ} \mathrm{C}$ in summer. The apparatus for vibration exposure was an electromagnetic shaker producing vertical sinusoidal vibration at a frequency of $60 \mathrm{~Hz}$, with an amplitude of $0.4 \mathrm{~mm}$ (root mean square). The vibration acceleration was $56.9 \mathrm{~m} / \mathrm{s}^{2}(5.8 \mathrm{~g})$. The noise exposure was 69 $\mathrm{dB}$ for the test rats and $67 \mathrm{~dB}$ for the control rats.

\section{NEUROPHYSIOLOGICAL MEASUREMENT}

The maximum motor conduction velocity (MCV), the amplitude of the evoked response, and the motor distal latency were measured on the tail nerve of each group every two months. The electrophysiological 
Figure 1 Schematic illustration of electrode. arrangement for measuring the motor conduction velocity on the tail nerve of $a$ rat. $A$ and $B$ are the stimulation points, $C$ is the recording point.

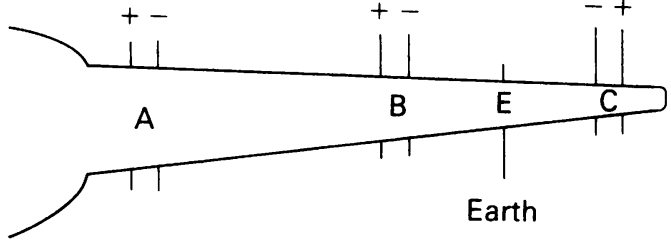

measurement was undertaken by the method of Misumi. ${ }^{1415}$ Figure 1 shows a schematic illustration of electrode arrangement for conduction velocity measurement in vivo. The tail nerve was stimulated by a square pulse of $0.3 \mathrm{~ms}$ duration, $1 \mathrm{cycle} / \mathrm{s}$, and supramaximal strength with an electrostimulator (MNS 1101, Nihon Kohden). With 20 repetitive stimuli under these conditions, the action potentials were superimposed and observed with a cathode ray oscilloscope (CRO, VC9A, Nihon Kohden), and then photographed. The test area for the MCV was A-B and distal latency was B-C (fig 1). During the measurement, the room temperature was kept at $27^{\circ} \mathrm{C}\left(\mathrm{SD} 0.5^{\circ} \mathrm{C}\right)$ and the tail was immersed in liquid paraffin at $34^{\circ} \mathrm{C}\left(0 \cdot 2^{\circ} \mathrm{C}\right)$.

EXAMINATION BY ELECTRON MICROSCOPY After 200, 500, or 800 hours of exposure, two rats from each group were anaesthetised with pentobarbitone $(30 \mathrm{mg} / \mathrm{kg}$ intraperitoneally). The tail nerve was exposed and fixed in situ with $2 \%$ glutaraldehyde (containing $1.5 \%$ formaldehyde) in $0.1 \mathrm{M}$ cacodylate buffer (pH 7.4) for 30 minutes. The nerve was cut into $1 \mathrm{~mm}^{3}$ pieces for further fixation and postfixed with $1 \%$ osmium tetraoxide for two hours. After postfixation, specimens were dehydrated and embedded in epikote (Merck, Germany). Thin cross sections or longitudinal sections made by diamond or glass knives and stained with uranyl acetate and lead citrate were examined under a Hitachi $\mathrm{H}-500$ electron microscope.

The diameters of the nerve fibres were determined in the cross sections of tail nerve by the method of McDonald, ${ }^{16}$ described in detail in the previous report. ${ }^{12}$

\section{Results}

CHANGES IN MAXIMUM MCV

The MCV of each group became faster during the first two months. Compared with the control group, the MCV of exposed groups became significantly slower in the fourth (group 3) and the eighth month (group 2) of exposure (fig 2).

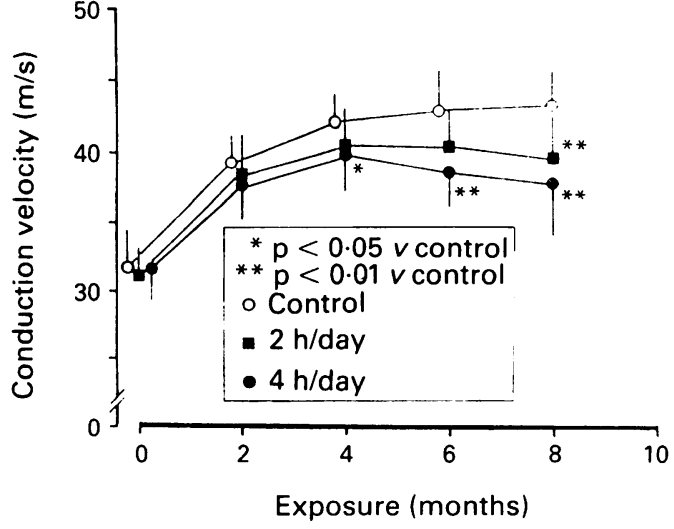

Figure 2 Changes in the maximum motor conduction velocity in the rat tail nerve induced by vibration. Numbers as in table 1.

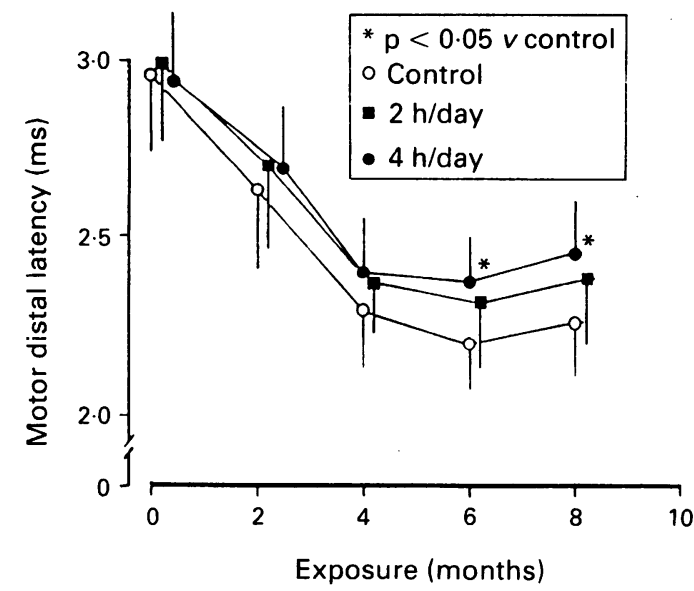

Figure 3 Changes in the motor distal latency of rat tail nerve induced by vibration. Numbers as in table 1.

CHANGES IN MOTOR DISTAL LATENCY

The motor distal latency in group 3 was delayed significantly compared with the control group after exposure for six months (600 hours vibration, fig 3 ).

\section{CHANGES IN AMPLITUDE OF THE EVOKED} RESPONSE

The amplitudes of the distal evoked responses were all higher than those of the proximal evoked responses without any significant difference in amplitudes of either the distal or proximal evoked responses, between the exposed and control groups, except in the group subjected to vibration for eight months (table).

Changes in the mean (SD) amplitudes ( $\mu V)$ of evoked responses induced by vibration

\begin{tabular}{|c|c|c|c|c|c|c|c|c|c|c|}
\hline \multirow[b]{2}{*}{ Groups } & \multicolumn{2}{|c|}{ Before $(n=12)$} & \multicolumn{2}{|c|}{2 Months $(n=12)$} & \multicolumn{2}{|c|}{4 Months $(n=10)$} & \multicolumn{2}{|l|}{6 Months } & \multicolumn{2}{|c|}{8 Months $(n=8)$} \\
\hline & $A C$ & $B C$ & $A C$ & $B C$ & $A C$ & $B C$ & $A C$ & $B C$ & $A C$ & $B C$ \\
\hline Control & $696(388)$ & $873(623)$ & $1112(552)$ & 1790 (999) & $1017(572)$ & $1403(864)$ & 997 (467) & $1505(782)$ & $1009(483)$ & $1613(796)$ \\
\hline $2 \mathrm{~h} /$ day & 595 (415) & $816(604)$ & $1186(746)$ & $1887(993)$ & 805 (366) & $1352(542)$ & $\begin{array}{l}887(594) \\
(\mathrm{n}=10)\end{array}$ & $\begin{array}{l}1131(586) \\
(n=10)\end{array}$ & $901(484)$ & $1007(599)^{\star}$ \\
\hline $4 \mathrm{~h} /$ day & $461(220)$ & $650(422)$ & $824(462)$ & $1490(756)$ & $954(576)$ & $1451(751)$ & $\begin{array}{l}942(572) \\
(n=8)\end{array}$ & $\begin{array}{l}1017(619) \\
(\mathrm{n}=8)\end{array}$ & $910(556)$ & $991(627)^{\star}$ \\
\hline
\end{tabular}

${ }^{\star} \mathrm{p}<0.05 v$ controls. $\mathrm{AC}=$ proximal evoked responses; $\mathrm{BC}=$ distal evoked responses. 
ULTRASTRUCTURAL CHANGES OF THE MYELIN SHEATH AND THE AXON

After 200 hours of vibration, only a fraction of the nerve fibres showed slight disruption of the myelin sheath and detachment of the sheath from the axon. By $\mathbf{5 0 0}$ hours of vibration, the sheaths were appreciably disrupted along the Schmidt-Lanterman incisures, clearly detached from the axolemma, and protruded into the axons (fig 4). When the vibration was up to 800 hours, part of the myelin sheaths disintegrated. Detachment of the sheath from the axolemma was severe and the axon was significantly constricted (fig 5).

\section{ULTRASTRUCTURAL CHANGES OF SCHMIDT-}

LANTERMAN INCISURES

The Schmidt-Lanterman incisures of the tail

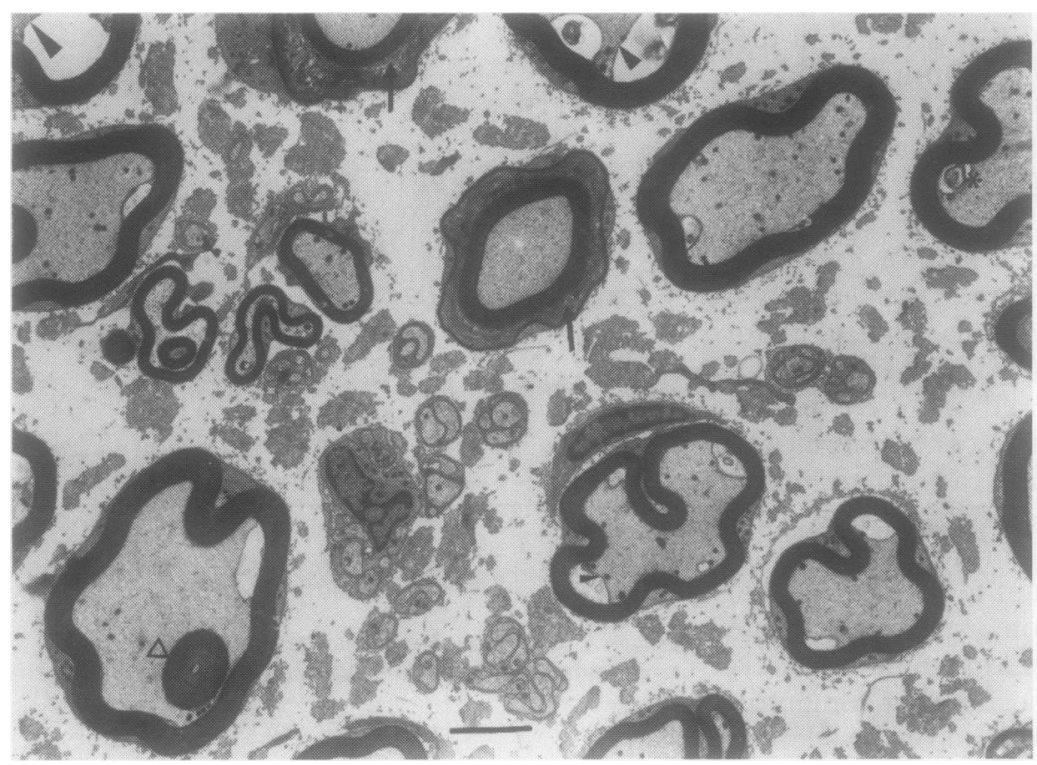

Figure 4 Cross section of rat tail nerve after 500 hours of vibration. Several myelin sheaths were disrupted (arrows), some protruded into axons (stars). Other myelin sheaths were detached from the axolemma (arrowheads). Small concentric myelin sheaths appeared in axons due to deformation of myelin sheaths (triangle). (Originally $\times 3800$ ) Scale bar $=3 \mu \mathrm{m}$.

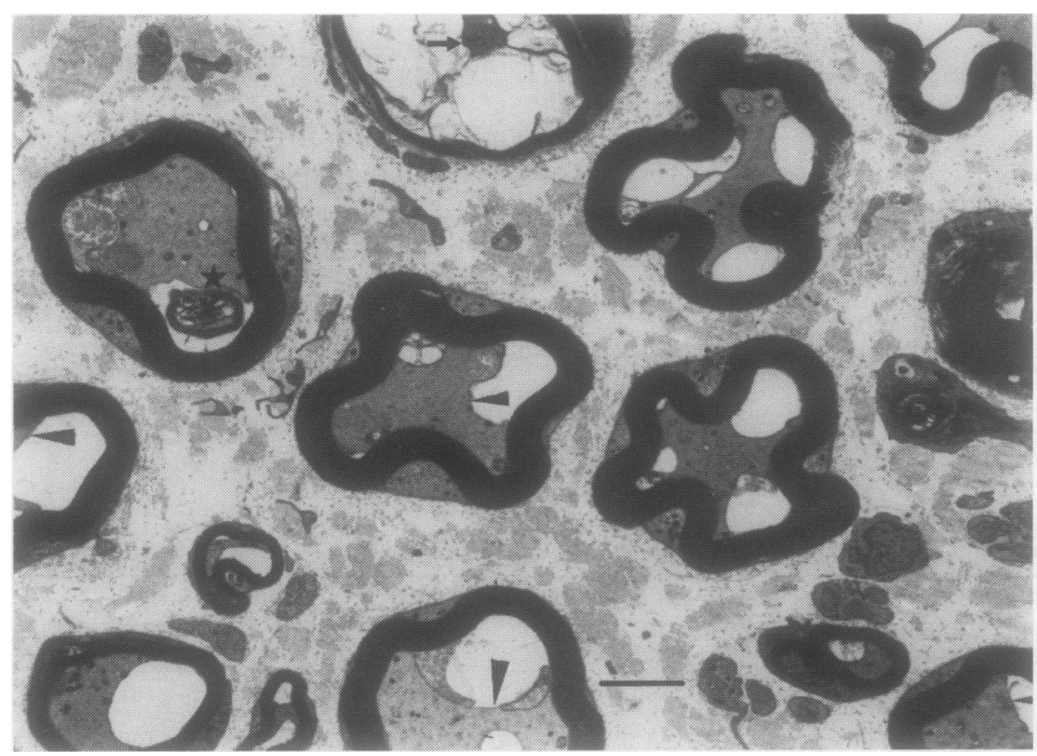

Figure 5 Cross section of rat tail nerve after 800 hours of vibration. One myelin sheath showed severe disruption and axonal constriction was prominent (arrow). Myelin sheaths were more detached from axolemma than after 500 hours of vibration (arrowheads) and protruded into the axon (star). (Originally $\times 3800$ ) Scale bar $=3 \mu \mathrm{m}$. nerves of control rats were usually closed or slightly open and cytoplasmic spirals seemed regular just the same as in the normal saphenous nerve of rabbits. ${ }^{12}$ There were characteristic stacks of desmosomoid structures near the surface of the nerve fibre (abaxial side). As the vibration dose increased, the SchmidtLanterman incisures dilated and the periincisural myelin sheath disrupted more severely; also, the density of the incisures increased. After 200 hours of vibration, the incisures dilated from the abaxial side bilaterally. By 500 hours of vibration, as well as severe dilatation of the incisures, cytoplasmic spirals showed an irregular arrangement (fig $6)$. When the vibration dose was up to 800 hours, part of the peri-incisural myelin sheath disrupted (fig 7).

ULTRASTRUCTURAL CHANGES IN THE NODE OF RANVIER

After 200 hours of vibration, the paranodal end loops seemed irregular. By 500 hours of vibration, many vacuoles accumulated in the nodal gap, the paranodal end loops showed an irregular arrangement, and some loops were detached from the paranodal axolemma (fig 8). When the vibration dose was up to 800 hours, the changes seemed more severe and part of the axon was destroyed (fig 9).

\section{Discussion}

Chronic exposure of a rat limb to sinusoidal vibration induces swelling in the nerve, which will lead to permanent damage to the nerve. ${ }^{17}$ The motor conduction velocity of the ulnar nerve was decreased among patients with carpal tunnel syndrome supporting the idea that entrapment neuropathies in the hands may be due to tissue swelling caused by vibration at work. ${ }^{18}$ An increase in fibroblast activity in rat peripheral nerves exposed to vibrations has been found. The fibroblast activity was more prominent in distal nerve branches than in the proximal portion. This indicates that nerves close to the vibration had most damage. ${ }^{19}$ After 20 hours of vibration, unmyelinated fibres in the plantar nerves of rats showed distinct changes, including deranged axoplasmic structure or accumulation of smooth endoplasmic reticulum. ${ }^{13}$ Lundborg et al suggested that the structural findings correlated well with functional tests, showing increased potential for regeneration based on a "conditioning lesion" induced by the vibration trauma. ${ }^{13}$ Our present study gives a new insight into ultrastructural changes in the peripheral nerve as a result of vibration and suggests that some of these changes may be responsible for the neurophysiological findings.

Our results indicate that prolonged vibration induces several ultrastructural changes in rat tail nerve: (1) detachment of the myelin sheath from the axolemma, (2) constriction of the axon, (3) protrusion of the myelin sheath into the axon, (4) accumulation of vacuoles in paranodal regions, and (5) dilatation of the Schmidt-Lanterman incisures. 


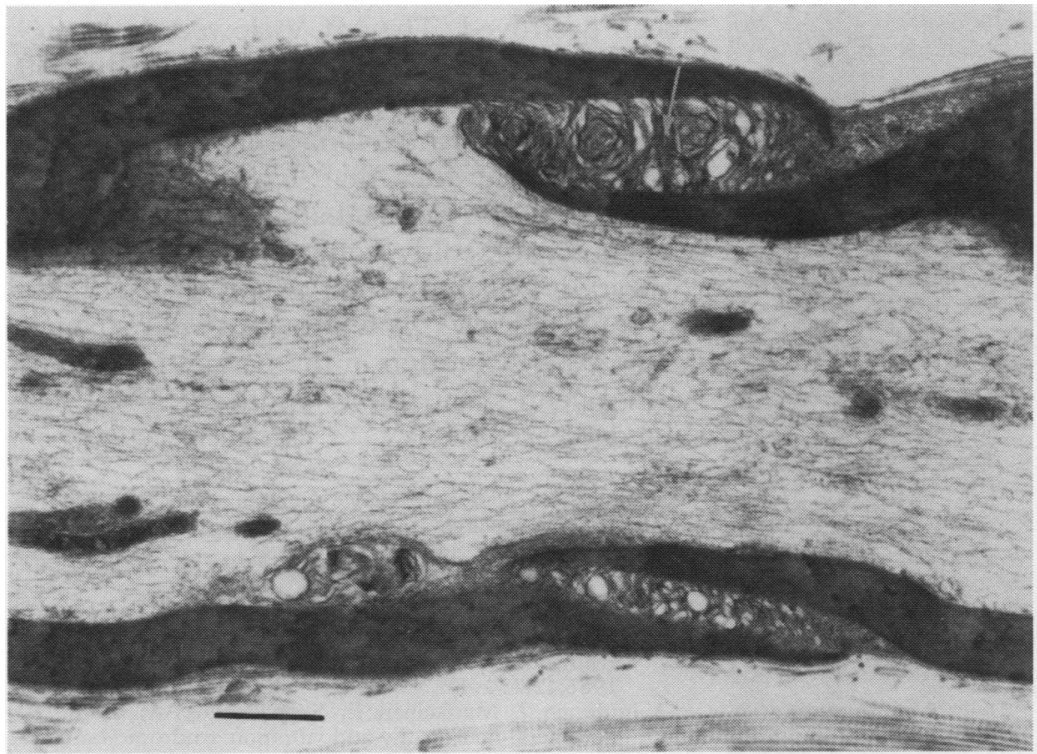

Figure 6 Longitudinal section of rat tail nerve after 500 hours of vibration. SchmidtLanterman incisures showed severe dilatation and cytoplasmic spirals were irregular (arrow). (Originally $\times 16800$ ) Scale bar $=1 \mu \mathrm{m}$

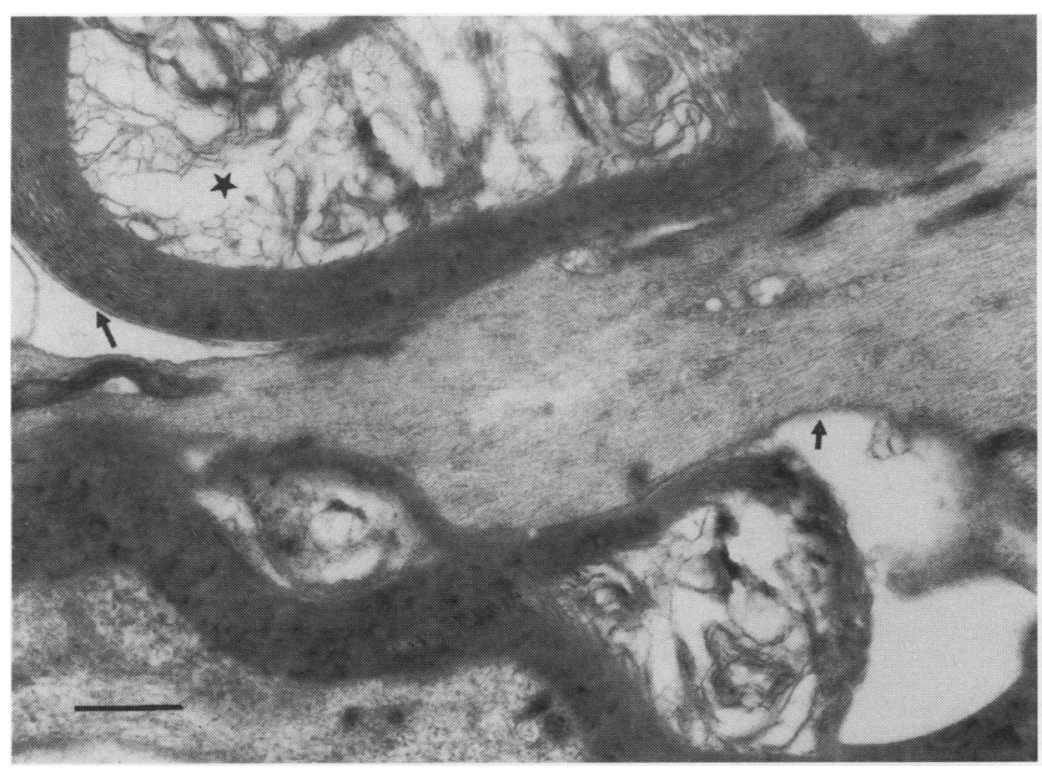

Figure 7 Longitudinal section of rat tail nerve after 800 hours vibration. SchmidtLanterman incisures showed severe dilatation and cytoplasmic spirals were very irregular (star). The detachment of the myelin sheath from the axolemma was prominent (arrows). (Originally $\times 15200$ ) Scale bar $=1 \mu \mathrm{m}$.

These are the same as findings in rabbit's saphenous nerve. ${ }^{12}$

It has been proposed that these changes caused by vibration may lead to peripheral nervous disturbances. ${ }^{120}$ Operation of vibrating tools, which involves exposure to combined stressors of local vibration, heavy work, climate, and noise, will affect the faster myelinated nerve fibre activity. ${ }^{21}$

The correlation between the amounts of vibration and the decrease in MCV was found among patients with carpal tunnel syndrome. ${ }^{18}$ In this study, after 400 hours of vibration the $\mathrm{MCV}$ of exposed groups began to decrease significantly compared with the control group. The reduction in MCV may be due to the ultrastructural changes in the paranodal regions and myelin sheaths. It has been shown that the paranodal regions play an important part in nerve conduction. They may act as a $\mathrm{Na}^{+}$source to control the rise of the action potential at the node of Ranvier. ${ }^{22-26}$ When there was 200 hours of vibration, the paranodal regions were only slightly damaged, which did not seem to have much effect on the function of the $\mathrm{Na}^{+}$ source, so the diminution of MCV was not significant (fig 2). After 500 hours of vibration, part of the paranodal end loops was detached from the axolemma and many vacuoles accumulated in the paranodal regions (fig 8); the $\mathrm{Na}^{+}$source in paranodal regions might decline and account for the fact that MCV had slowed down significantly (fig 2). After 800 hours of vibration, paranodal end loops showed an irregular arrangement and were detached from the axolemma (fig 9), which resulted in a further decrease in MCVs (fig 2). These findings indicate that the ultrastructural changes in paranodal regions induced by vibration may cripple the cyclic movement of $\mathrm{Na}^{+}$involved in saltatory conduction at the node of Ranvier, which causes the reduction in MCVs. ${ }^{23}$

The ultrastructural changes in the myelin sheath, the axon, and Schmidt-Lanterman incisures may also be responsible for the diminution of $\mathrm{MCV}$. The nerve conduction velocity of the myelinated fibre is directly proportional to the diameter of the nerve fibre and axoplasm conductance but inversely proportional to membrane capacitance of the myelin sheath. ${ }^{27}$ As noted, when the vibration lasted 500 hours, MCV had slowed down significantly. In the meantime, several myelin sheaths were disrupted, some were detached from the axolemma (fig 4), and SchmidtLanterman incisures were severely dilated (fig $6)$. By 800 hours of vibration, the axonal constriction was prominent (fig 5) and part of the peri-incisural myelin sheath was disrupted (fig 7). The dilatation of the SchmidtLanterman incisures, disruption of the periincisural myelin sheath, and detachment of the myelin sheath from the axolemma may decrease the radial resistance and increase the membrane capacitance. The constriction of the axon reduces the axonal cross section area and thus reduces the conductance of the axoplasm. This will cause the reduction in MCV, so it is suggested that the reduction in MCV induced by vibration may also be due to the destruction of the myelin sheath, the constriction of the axon, and the dilatation of Schmidt-Lanterman incisures.

The destruction of the myelin sheath was present after 200 hours of vibration, but the constriction of the axon occurred as late as after 500 hours of vibration. It seemed that the ultrastructural changes induced by vibration in the myelin sheath appeared before those in the axon. This was confirmed in the neurophysiological examination. The disruption of the myelin sheath is first reflected in the slowing of MCV; however, the degeneration of the axon is reflected in decrease in amplitudes of evoked responses. ${ }^{28}$ After 400 hours of vibration, the MCV was reduced significantly, but the amplitudes of evoked 


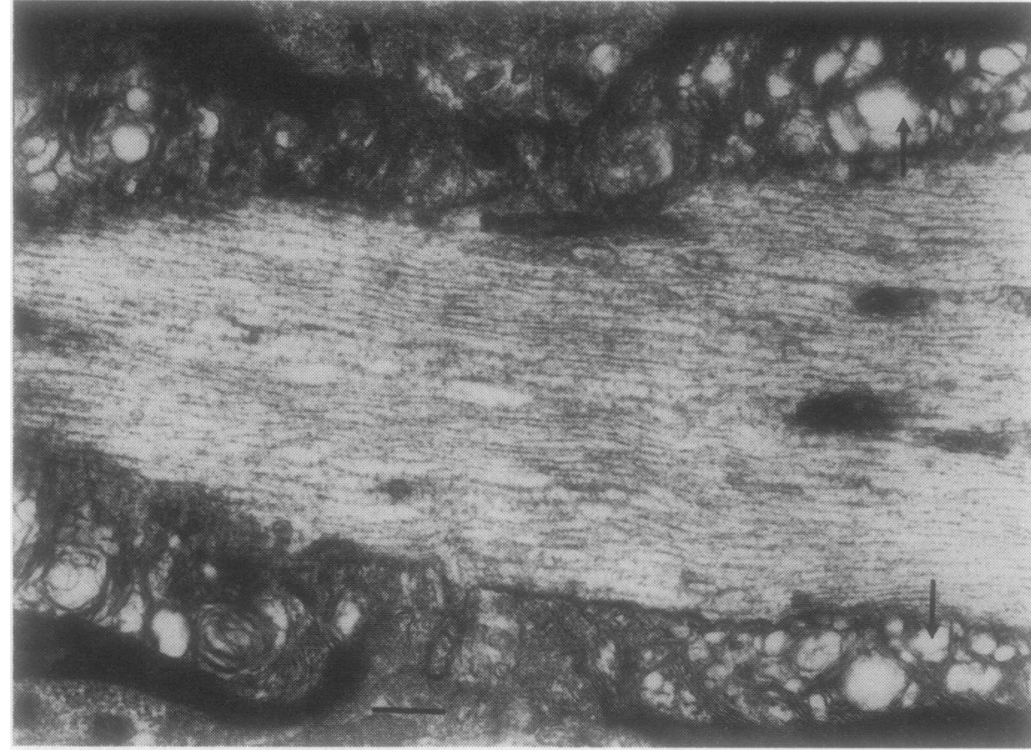

Figure 8 Longitudinal section of rat tail nerve through the node of Ranvier after 500 hours of vibration. Paranodal end loops were irregular and many vacuoles had accumulated (arrows). (Originally $\times 28$ 500) Scale bar $=0.4 \mu \mathrm{m}$.

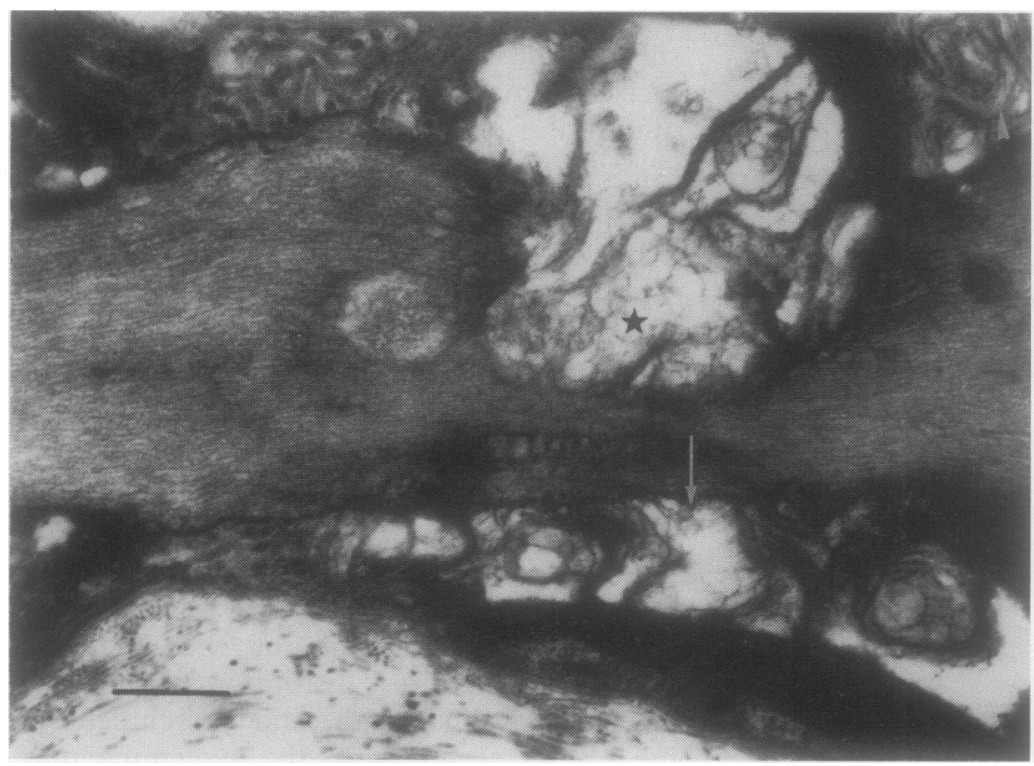

Figure 9 Longitudinal section of rat tail nerve through the node of Ranvier after 800 hours of vibration. Paranodal end loops showed irregular arrangement (arrowhead) and were detached from axolemma (arrow). Part of the axon was destroyed (star). (Originally $\times 19000)$ Scale bar $=1 \mu \mathrm{m}$.

responses did not decrease significantly until 800 hours of vibration.

It was found that the myelinated fibres in the rat tail nerve were from 2 to $8 \mu \mathrm{m}$ in diameter. After 500 to 800 hours of vibration, the sheath-disrupted fibres were mainly from 4 to $8 \mu \mathrm{m}$ in diameter. This indicated that vibration caused the disruption of the myelinated fibres with larger diameters. The MCV represents the conduction velocity of larger fibres in the proximal tail nerve ( $A$ to $B$ ), whereas the motor distal latency expresses the conduction of the distal tail nerve (B to C, fig 1 ), the conduction of the nerve branching from the tail nerve into muscle, and the delay time at neuromuscular junctions. Thus the delay of motor distal latency implies that the smaller fibres at the distal end of the tail nerve and neuromuscular junctions may have been destroyed. The MCV slowed down significantly when the vibration was up to 400 hours (fig 2), but the motor distal latency did not get significantly longer until 600 hours (fig 3), suggesting that larger nerve fibres were destroyed earlier than smaller ones.

Thus, our study confirms that prolonged vibration will induce nerve fibre damage and strongly suggests that ultrastructural changes induced by vibration in the paranodal regions and myelin sheaths may be involved in causing decreased $\mathrm{MCV}$.

We thank the National Science Council of the Republic of China for the research grant (No NSC-77-0412-B037-12) to support this work.

1 Pyykkö I. Clinical aspects of the hand-arm vibration syndrome: a review. Scand $f$ Work Environ Health 1986;12:439-47.

2 Juntunen J, Matikainen E, Seppäläinen AM, Laine A Peripheral neuropathy and vibration syndrome-a clinical and neurophysiological study of 103 patients. In Arch Occup Environ Health 1983;52:17-24.

3 Hisanaga $\mathrm{H}$. Studies of peripheral nerve conduction velocities in vibrating tool operator. fapanese fournal of Industrial Health 1982;24:284-93.

4 Kaji H, Niioka T, Nagatsuka S, Yasuno Y, Honma $H$ Sato $E$, Saito $K$. Evaluation of sensory nerve functions in patients with vibration disease with reference to cervical spondylosis. In: Okada A, Taylor W, Dupuis H, eds. Hand-arm vibration. Kanazawa: Kyoei Press Company, $1990 ; 259-61$.

5 Harada N, Matsumoto T. Vibration disease in an iron foundry. Proceedings of Ninth Asian Conference on Occupational Health. Seoul, Korea: 1979:253-7.

6 Verberk MM, Sall'e HJA, Kempers O. Vibratory and tactile sense of the fingers after working with sanders. In Arch Occup Environ Health 1985;56:21 7-23.

7 Suzuki $H$. Vibration syndrome of vibrating tool users in a factory of steel foundry. Part 2. Disturbances of the cutaneous senses and the blood flow of fingers. fapanes fournal of Industrial Health 1978;20:269-75.

8 Ho ST, Yang MS, Wang CH, Hong MY. Investigation on the disturbances of the peripheral nervous function of the cooling-work workers. foumal of Technology 1989;4: 323-9.

9 Cherniack MG, Letz $R$, Gerr F, Brammer A, Pace $P$ Detailed clinical assessment of neurological function in symptomatic shipyard workers. Br ₹ Ind Med 1990, 47:566-72.

10 Takeuchi T, Futatsuka M, Imanishi H, Yamada S. Pathological changes observed in the finger biopsy of patients with vibration-induced white finger. Scand $\mathcal{F}$ Work Envinon Health 1986;12:280-3.

11 Takeuchi $T$, Takeya $M$, Imanishi $H$. Ultrastructural changes in peripheral nerves of the fingers of three vibration-exposed persons with Raynaud's phenomenon. Scand o Work Environ Health 1988;14:31-5.

12 Ho ST, Yu HS. Ultrastructural changes of the peripheral nerve induced by vibration: an experimental study. $\mathrm{Br} \mathscr{F}$ Ind Med 1989;46:157-64.

13 Lundborg G, Dahlin LB, Hansson HA, Kanje M Necking LE. Vibration exposure and peripheral nerve fiber damage. $\mathcal{F}$ Hand Surg [Am] 1990;15A:346-51.

14 Misumi J. Induction of action potentials and determining method of maximum conduction velocity of mixed nerve in rat's tail. fapanese fournal of Industrial Health 1975;17:172-3.

15 Misumi J, Nagano M. Experimental study on the enhancement of the neurotoxicity of methyl n-butyl ketone by non-neurotoxic aliphatic monoketones. $\mathrm{Br} \mathcal{F}$ Ind Med 1985;42:155-61.

16 McDonald DM. Morphology of the rat carotid sinus nerve. II Number and size of axons. Fournal of Neurocytology 1983;12:373-92.

17 Lundborg G, Dahlin LB, Danielsen N, Hansson HA, Necking LE, Pyykkö I. Intraneural edema following exposure to vibration. Scand $\mathcal{f}$ Work Environ Health 1987;13:326-9.

18 Koskimies K, Farkkila M, Pyykkö I, Jantti V, Aatola S, Starck J, Inaba $R$. Carpal tunnel syndrome in vibration disease. Br $\mathcal{Y}$ Ind Med 1990;47:41 1-6.

19 Hansson HA, Dahlin LB, Löwenadler B, Lundborg G Paleus S, Skottner A. Transient increase in insulin-like growth factor I immunoreactivity in rat peripheral nerves exposed to vibrations. Acta Physiol Scand 1988; 132:35-41.

20 Tseng HM, Yu HS, Ho ST, Yao TH. Vibration syndrome-pathophysiological and electron-microscopic studies. Kao Hsiung I Hsueh Ko Hsueh Tsa Chih 1986; 2:732-44.

21 Murata K, Araki S, Maeda K. Autonomic and periphera nervous system dysfunction in workers exposed to handarm vibration: a study of $R-R$ interval variability and distribution of nerve conduction velocities. Int Arch Occup Envinon Health 1991;63:205-11. 
22 Tao-Cheng JH, Rosenbluth J. Nodal and paranodal membrane structure in complementary freeze-fracture replicas of amphibian peripheral nerves. Brain Res 1980 199.249-65.

23 Wiley DA, Ellisman MH. Rows of dimeric-particles within the axolemma and juxtaposed particles within glia, incorporated into a new model for the paranodal glial-axonal junction at the node of Ranvier. $f$ Cell Biol 1980;84:281-93.

24 Tippe A, Müller-Mohanssen $H$. Further experimental evidence for the synapse hypothesis of $\mathrm{Na}^{+}$current activation and inactivation at the Ranvier node. Naturwissenschaften 1975;62:490-1.

25 Ellisman MH, Friedman PL, Hamilton WJ. The localiza- tion of sodium and calcium to Schwann cell paranodal loops at nodes of Ranvier and of calcium to compact myelin. Fournal of Neurocytology 1980;9:185-205.

26 Wood JG, Jean DH, Whitaker JN, McLaughlin BJ, Albers RW. Immunocytochemical localization of the sodium potassium activated ATPase in knifefish brain. fournal of Neurocytology 1977;6:571-81.

27 Moore JW, Joyner RW, Brill MH, Waxman SD, Najar-Joa $M$ Simulations of conduction in uniform myelinated fibers. Biophys $\mathcal{F}$ 1978;21:147-60.

28 Bergmans JA. Neurophysiological features of experimental and human neuropathice In: Bergmans JA, and him and biological aspects of peripheral 